\title{
$\begin{array}{ll}\text { Research Square } & \text { Preprints are preliminary reports that have not undergone peer review. } \\ \text { They should not be considered conclusive, used to inform clinical practice, }\end{array}$ or referenced by the media as validated information. \\ The Role of Participatory Action Research on Clinicians' Attitudes toward Medication Management
}

\section{Fatemeh Bakhshi}

Tehran University of Medical Sciences School of Nursing and Midwifery

Rebecca Mitchell

Macquarie University Macquarie Graduate School of Management

\section{Alireza Nikbakht Nasrabadi}

Tehran University of Medical Sciences School of Nursing and Midwifery

\section{Mostafa Javadi}

Shahid Sadoughi University of Medical Sciences and Health Services

Shokoh Varaei ( $\nabla$ shvaraei@sina.tums.ac.ir)

Tehran University of Medical Sciences School of Nursing and Midwifery https://orcid.org/0000-00029238-0340

\section{Research}

Keywords: Participatory action research, medication management, medication safety, emergency department, clinicians, attitudes

Posted Date: November 13th, 2020

DOl: https://doi.org/10.21203/rs.3.rs-104487/v1

License: (c) (i) This work is licensed under a Creative Commons Attribution 4.0 International License. Read Full License 


\section{Abstract}

Background: Medication management is a cyclic and multidisciplinary approach to enhance safe medication therapy. This paper explores clinician attitude toward medication management which is both open to influence and strongly linked to successful changes in mediation behavior.

Purpose: To investigate effects of engaging in participatory action research to improve emergency medicine clinicians' attitudes toward implementing effective medication management.

Methodology: Data are drawn from two-cycle participatory action research. Within the study, a total of 85 clinicians including nurses and physicians from emergency department of one university affiliated hospital participated as participants. Eight managers and clinicians participated as representatives. Initially, a situation analysis on the current medication management and clinician views regarding medication management was conducted using three focus groups. Evaluation and reflection data were obtained through qualitative interviews. All qualitative data were analyzed using content analysis.

Results: Clinicians initially expressed negative attitudes toward existing and new plans for medication management, in that they were critical of current medication-related policy and procedures, as well as wary of the potential relevance and utility of potential changes to medication management. Through the action research, improvement actions were implemented including interprofessional courses, pharmacistled interventions, and the development of new guidelines regarding medication management. Participants and their representatives were engaged in all participatory action research stages. Extracted results from evaluation and reflection stages revealed that by engaging in the action research and practice new interventions, clinicians' attitude toward medication management was improved.

Conclusion: The results support the impact of participatory action research on enhanced clinicians' positive attitudes through involvement in planning and implementing medication management actions.

\section{Contributes To The Literature}

- This research identifies that frontline clinician attitudes and their involvement are key interrelated factors that determine how managers can address medication management-related issues.

- This work provides important information regarding the role of participatory action research on improving clinicians' positive attitudes and intentions toward medication management.

- Our findings suggest how implementation of organizational change regarding medication management can be sustained.

- Collaboration of frontline staff and managers consistent with interprofessional safe medication therapy are related to promoted medication safety culture.

\section{Background}


The Emergency Department (ED) is a hospital setting that poses many patient safety challenges, including highly unpredictable conditions and frequent use of high-risk medications (1). These conditions increase the risk of medication errors (2). Medication management has been evidenced as a strategy to address patient safety challenges related to the medication errors (3). Medication management is a cyclic approach to enhance safe and effective medication therapy in healthcare (4). This approach is essentially multidisciplinary and typically involves a range of healthcare clinicians including pharmacists, nurses, and physicians. It reflects a process in which medications are selected, procured, delivered, prescribed, reviewed, administered and monitored to assure high quality patient care (5).

Medication safety is the process and the product of medication management and relies heavily on a strong safety culture. Building a safety culture involves building alignment between individual, group and institutional values related to safety, which impacts attitudes, perceptions and generally the patterns of behavior of clinicians (6). To achieve patient safety as a primary outcome of medication management, we need to focus on two constituent structures of safety culture, including safety climate and safety tools. Safety tools refers to all types of safety procedures and tools that physically develop the safe environment (7), while safety climate refers to shared perceptions and attitudes of clinicians concerning safety as a priority (8). Safety climate is a unit-level construct and represents individuals' collective perception of safety priorities and practices in their organization (9).

Predominantly, from a managerial perspective, establishing safety tools might be a sufficient component for medication management. However, clinicians' attitudes and behaviors are likely underestimated by explicit emphasis on safety tools. Since clinicians act as clinical leaders in the healthcare settings, their attitudes are likely to be a determining factor for successfully implementing safety initiatives (7).

This study employs Participatory Action Research (PAR) with the aim of facilitating medication management implementation and driving a process of collaborative enquiry. PAR is an approach which facilitates change through involving participants and focusing on their attitudes (10). PAR has been demonstrated to engender positive attitudes on the basis of organizational citizenship, including in healthcare settings, and increases clinician perceptions of self-worth and competence (11).

We aimed to address the following questions: Can engaging in PAR improve clinicians' attitudes to medication management in support of its effective implementation?

This study contributes to the broad literature on medication management in the healthcare settings. To the best of our knowledge, the extant literature lacks consideration of the role of clinician attitude in establishing effective medication management interventions in the ED. In particular, no action research has been undertaken on this topic which limits our knowledge of the processes that may contribute to successful medication management intervention development and participative implementation.

\section{Methods}


We used a model of PAR incorporating cyclical activities based on Kemmis and Mctaggart (12). PAR cyclical activities include observation, reflection, plan and action. The PAR approach provided us with the opportunity to involve clinicians and concurrently consider their attitudes toward medication mangement and its influence on ED safety culture.

\section{Research setting}

The study setting was an ED of a public hospital and trauma center. The 32-bed emergency unit provided comprehensive emergency patient care. The ED clinicians include nurses, emergency medicine specialists, and emergency medicine residents.

\section{Participants}

Participant involvement was initiated subsequent to the identification of the research question. We used an intentional sampling method to recruit ED clinicians (13) including emergency medicine specialists $(n=12)$, emergency nurses $(n=55)$ and emergency medicine residents $(n=20)$. Since it was impossible for all ED clinicians to participate in every PAR stage, our study was organized around two levels of participation. Clinicians with a greater degree of participation were termed "representatives". They contributed directly and acted as boundary-spanners, connecting to other participants throughout the study. These representatives collated and conveyed information regarding perceptions and attitudes of other participants. Representatives were selected using purposive sampling and included both formal decision-makers (e.g., clinical and administrative leadership) and managers or clinicians who routinely engaged in ED activities (ED nurses and physcians). Two emergency medicine specialists, two clinical and educational supervisors, two experienced ED nurses, one nursing faculty member, and one clinical pharmacist were representatives $(n=8)$. All other clinicians with lesser degree of involvement called "participants". Participants were heavily involved in the implementation of the new study actions and in feeding their perceptions and suggestions to representatives.

\section{Data collection}

Data were collected from August 2018 to October 2019. A qualitative methodology was used for data collection, specifically face-to-face focus group discussions and interviews. Table 1 illustrates the two phase of PAR, their stages, timeline for each stage and the clinicians who participated in each stage as representatives or participants. See additional file 1 for Consolidated Criteria for Reporting Qualitative Research (COREQ) checklist.

\section{Phase l:}

\section{Stage 0: Informal preliminary interviews}

Prior to initiating the formal study, we conducted informal interviews. More specifically, we asked clinicians to describe features of their work environment related to medication management and their perceptions regarding change readiness. We aimed to identify their initial attitudes and the existing safety 
culture related to medication management. Participants consistently noted the absence of well-organized medication management and some weaknesses in safety behavior which they linked to limited safety tools and poor safety climates. They voiced concerns regarding the potential for new medication management initiatives to be developed and implemented, largely attributed to their lack of knowledge and power.

\section{Stage 1. Situation analysis}

In the initial PAR stage, we analyzed the current safety culture and clinicians' attitudes related to medication management by implementing three focus group discussions. We developed a focus group discussion guide (14) based on preliminary data gathered. Next, we distributed the guide to representatives. To initiate each focus group the facilitator (FB) welcomed invitees and presented an introduction. Then, the focus group logistics and guidelines were articulated. Main questions included: How would you describe the medication management in the ED? During recent years, did you see any change in medication management? What is your opinion about improving plans for medication management? What strategies would facilitate implementing new medication management programs?

\section{Stage 2 and 3. Plan and Action}

In the second stage, a Professional Co-development Group was established (15). The group members were the same representatives. The aim of creating the group was to involve clinicians' in the development and implementation of changes. First, the group members established and implemented a process for selecting actions which focused on feasibility in the context of existing resources. Second, the group developed interprofessional plans for implementing selected actions. Actions were accomplished in stage three of the PAR and involved all ED clinicians. The hospital management team provided financial support to enable the implementation of selected actions.

\section{Stage 4. Observation}

We organized a fourth group discussion to evaluate participants' attitudes regarding the new actions for medication management. Similar representatives as in stage one took part. A summary of previous stages was provided. Main questions included: How would you describe the new changes in medication management? Do you detect any improvement regarding medication therapy by ED clinicians? Do you ever have concerns about your role in processing safe medication therapy? What is your assessment of other professionals and their role in medication safety? Did you experience changes in the collaborative climate of the ED? How would you describe the medication management in the ED?

\section{Stage 5. Reflection}

Reflection in PAR aims to clarify the issues, progress and developments in the subject under research. To this end, interviews were conducted with participants across different shifts. We used an interview guide that was developed based on previous stages (16). The main open questions in the interviews were as follows: Did the new actions make differences regarding medication management? How much did the 
actions influence your attitudes about medication management in ED? Were the actions justifiable based on the current conditions in ED? To what extent has your input been reflected in new medication management actions? Based on progression of interviews, exploratory questions were asked. Each interview ended with reflecting and summarizing.

\section{Phase Il:}

In the second phase, the Professional Co-development Group developed new and amended strategies that were designed based on data derived during the previous reflection stage. Newly designed actions in second phase were implemented by participation and involvement of ED clinicians. Next, we conducted semi-structured interviews to observe and evaluate clinicians' attitudes regarding the implementation of new plans. We asked participants the same questions as in the observation stage in the first phase. The question "were you satisfied with the new guidelines in medication management?" was added, related to the new actions that were implemented in the second phase. For the last stage, a final reflection process was undertaken in a manner similar to the first phase.

The principal researcher (FB) who is experienced in qualitative interviewing conducted the interviews. During interviews field notes were taken to enable content analysis. Each group discussion lasted 1-2 hours and interviews took 20-30 minutes.

\section{Data analysis}

All focus group discussions and interviews were audio recorded and transcribed with permission. Transcripts of group discussions and interviews were analyzed based on conventional qualitative content analysis drawing on the Graneheim and Ludman's method (17). Since each PAR stage was directed by specific aims and interview questions, analysis of group discussions and interview transcripts was stagebased.

To ensure coding agreement and address inter-rater reliability (18), we double coded the first group discussion transcript (20 pages). There was $85 \%$ agreement between two reviewers. After reviewers completed coding of all transcripts, differences in coding between two reviewers were resolved through research team and participants discussion. MAXQDA software version 18 was used to manage the data. Data saturation was the main criteria to end the interview process.

We sought to maximize rigour and trustworthiness by adopting the Guba and Lincoln guidelines to ensure the reliability of the results (19). Participant checks for accuracy of data were implemented by discussing findings and interpreted data with participants. Multiple data sources were used to enable data triangulation and clinicians from nursing, medical and pharmacy professions were provided with data and analysis to ensure interprofessional views were accurately captured. Multiple researchers in the research team participated in different phases of PAR.

\section{Results}


The main findings of two phases of the PAR are presented in this section.

\section{Phase I}

After analyzing focus group discussions, three major themes with subthemes were extracted from discussions: 1) Attitudes toward medication management, 2) Barriers toward medication management, and 3) Facilitators of medication management.

Attitudes toward medication management: Representatives described feeling responsible for medication safety. However, they perceived unfavorable conditions and reported mostly negative attitudes toward implementing new plans for medication management in the ED.

\section{- Discontinued implementation of new medication management approaches}

In some situations, medication management procedures, even those that were relatively recently implemented, were changed due to the appointment of a new manager. This led to a negative attitude toward new plans.

"Sometimes before we adopt new plans, the new manager comes and try to change it, so we prefer to stay in routines" (Focus group discussion 2)

\section{- Attitude toward superiors}

The importance of respective status differentials between managers and clinicians was mentioned by all representatives. This reportedly induced humiliation and reluctance in many clinicians to expressing their negative perceptions regarding existing medication management approaches.

"I'm reluctant to complain about current medication management conditions to my superiors, because it may offend him..." (Focus group discussion 1)

- Medication therapy in complicated moments

Participants questioned the responsiveness of medication management process, particularly during ED high volume periods.

"How about the shift works that we concurrently are surrounded with lots of acute patients? How is medication management applicable in these situations?" (Focus group discussion 1)

Barriers toward medication management: There were many barriers toward medication management in ED reported by representatives. These barriers influenced clinicians' attitudes toward medication management.

- Individual-oriented perspective of failure 
Representatives stated that medication errors are often considered as active failures. This means that individuals are perceived as responsible for medication errors.

"Many superiors believe that everyone is solely responsible for the safety of the medication therapy he or she is doing, but it's short-sighted view" (Focus group discussion 3)

- Lack of effective feedback

The need for appropriate feedback regarding medication therapy from a qualified person was stressed by representatives.

"...it seems there are few efforts for giving proper feedbacks on medication therapy..." (Focus group discussion 1)

Facilitators of medication management: Several facilitators were identified as potentially supporting the improvement of medication management and positive attitudes toward improving medication management.

\section{- Medication safety training}

Representative endorsed that, when clinicians become more knowledgeable about medication therapy and medication management, they are more likely to participate in the improvement of medication management plans.

"The more effort is put into pharmaceutical education, the more people's knowledge and perception of safe medication will be improved" (Focus group discussion 3)

\section{- Enhancing a system-oriented perspective}

Participants stated that to benefit from medication management, a shift toward system-based practice was required. This suggested the benefit of sequential medication management steps and the application of resources to provide medication therapy that is of optimal value.

“...medication management is a systemic function, the more holistic we consider it, the better we will achieve..." (Focus group discussion 3)

\section{- Interprofessional collaboration}

Participants perceived that interprofessional forums, education and practice are required to allow clinicians from different professions to understand each other roles regarding medication, which would facilitate greater collaborative work.

"The medical and nursing professionals need to recognize each other's responsibility... when we are knowledgeable on the other professions' role through the medication management, so we can do it collaboratively..." (Focus group discussion 3) 
Actions in the first phase included interprofessional courses on medication management and placement of clinical pharmacists. Clinical pharmacists led the actions and all ED clinicians participated collaboratively. The planned and implemented actions in phase I is described in Table 2.

The fourth focus group discussion was run for observing the impact of actions. During this session, representatives discussed their experiences and attitudes toward new medication management procedures. Major categories derived from this group discussion were as follows:

- Increased willingness to adhere to medication management protocols

After training and interactive discussions, clinicians were encouraged to adhere to medication management protocols.

"...now we're noticed about the importance of guidelines. Before the courses with considered them as boring written materials..." (a nurse with 7-year experience)

- Motivated medication error reporting

During training, medication error scenarios were presented, which assisted clinicians to recollect similar situations and recall their mistakes. Hence, they were motivated to and confident to report their medication errors.

“...presented cases about medication errors were great, we imagined ourselves in those situations ..." (a nurse with 12-year experience)

- Interprofessional collaboration

As clinicians became aware of each other's roles, they were more committed to participating in new medication management procedures.

"...now I believed that medication management is like a puzzle and healthcare professionals should try to solve it collaboratively." (an emergency medicine specialist with 8-year experience)

At four months post-implementation, informal interviews with nine clinicians (participants) were conducted to allow for reflection on new medication management procedures. Major extracted categories can be labeled into two groups:

\section{Satisfaction with current action:}

- Well-informed clinicians: Participants reported being satisfied with the courses and training on medication guidelines. ED clinicians reported being more knowledgeable regarding safe and collaborative medication management.

- Robust medication safety: Clinicians stated that improved medication management had increased the robustness of medication therapy, such that peak ED volume did not lead to disruptions in 
medication policy adherence.

\section{Suggestions for new actions:}

- Context based guideline development: Participants believed that the current instructions regarding medication management and safety-related issues needed to be better promoted. They deduced that general guidelines and instructions were not sufficiently contextualized and practical.

- Clinician-oriented actions: Although clinicians mostly emphasized that the PAR approach was indeed participative and they collaboratively managed medication therapy, they still felt potential for a more active role. They mentioned that actions in the first phase were mostly pharmacist-led.

\section{Phase II.}

Based on data gathered and analyzed in the reflection stage of the first phase, the professional codevelopment group decided to continue implementing new actions for an additional four months. They decided that the interprofessional courses on medication management needed to be continued to stabilize the newly created safety climate. Development of more structured, context-specific and evidence-based medication management guidelines reflected another action. This new guideline which was developed collaboratively by ED clinicians aimed to diminish the authoritarian approach induced by previous guidelines and help clinicians to promote an understanding of their important role. The actions that were employed in the second phase are summarized in Table 3.

We conducted six interviews in the second phase observation stage with representatives. Three main categories emerged from data analysis regarding participants' evaluation of new actions:

- Safe medication therapy

Overall, participants assumed that new procedures improved medication safety.

"If I want to make a comparison about medication management since last year, the most important change is more safety..." (a nurse with 9-year experience)

\section{- Confidence}

Through the PAR, clinicians developed confidence in the ability of share their opinions, especially regarding medication management.

"...I think I have gained more courage to express my ideas for improving the system..." (a nurse with 5-year experience...)

- Observable outcome

Participants assumed that the new actions resulted in apparent and effective outcomes. 
"...there had been a lot of research and plans before, but usually the results were not very obvious, this time it was different..." (an emergency medicine specialist with 4-year experience)

The final reflection stage was the final PAR component. This included results from informal interviews with 10 clinicians. Most of the participants indicated that the actions in both phases had improved medication management and patient safety. We classified findings into two groups:

Safety attitudes improvement related to medication management: Findings under this theme related to changes and improvement in clinician safety attitudes, perceptions and behaviors following new actions in the ED:

- Inter and intra professional teamwork: Collaborative implementation of actions affected clinicians' perception of safety climate and teamwork. Participants emphasized the role of teamwork as major element to progress medication therapy among and between medical, nursing and pharmacy professionals.

- Psychological support: A more positive attitude not only resulted in safety-based practice, but also enhanced clinician wellbeing by limiting stress related to medication-related anxieties.

- Communication pathway: Participants realized that managers facilitated more reliable communication. This accompanied perceptions of openness and support among clinicians related to sharing their views and concerns.

- Perceived accountability: Participants perceived that no matter what profession or role, they are responsible for developing strong and positive safety attitudes regarding medication therapy.

Safety tool induced improvement in medication management: These findings related to the impact of newly introduced safety tools and related actions:

- Respected professional competence: Involving participants and their representatives in planning and implementing actions, especially in the development of new guidelines as a safety tool was interpreted as respecting clinicians' professional competence.

- Continuous improvement: Clinicians perceived that participating in courses and educational events led by pharmacists were important continuing in-service education that benefited their practice.

\section{Discussion}

The initial Results of the qualitative situation analysis revealed clinicians' negative attitudes toward changing the current medication management. Such negative attitudes would likely impede efforts towards medication management change $(20,21)$.

Through the PAR we engaged a range of clinicians, from managers to frontline clinicians to develop and implement new medication management actions. By employing PAR, we explicitly valued participants' competencies, empowered them to develop and implement changes, shared decision-making and ultimately engaged their collaboration (22). 
The analyzed data from forth group discussion captured primary changes in clinicians' attitudes regarding medication management. Participants reported increased motivation to adhere to medication management guidelines, and recognition of the importance of interprofessional approaches to medication therapy. This is a particularly useful given a recent quasi-experimental study that reported significant improvement in medication safety behaviors followed by interprofessional education (23). In addition, we found that pharmacists were useful mentors and guides to develop medication management skills and motivate clinician efforts to mitigate medication-related harms (24). Brown et al. underlined pharmacists' educational role to optimize medicinal practice (25).

Through the second phase, the majority of participants were engaged to develop medication management guidelines. Feeling useful and confident contributed to the development of positive attitudes towards changed medication management guidelines. This result is consistent with literature which suggests that strategies which increase staff perceived control over particular situations, including interdisciplinary communication and collaboration are likely to strengthen their intention to change and positive attitudes towards intended behavior (26).

The study culminated with participants' reflection on the whole PAR. Participants emphasized teamwork psychological support and perceived accountability as new elements were central to the development of new medication management-related safety attitudes and climate. This aligns with a recent systematic review that reported teamwork, communication and management support to be central to positive safety attitudes (27).

\section{Limitation And Strenghts}

This study has both strengths and limitations. The current PAR process successfully engaged participants and provided in-depth situation analysis of a specific context in order to inform action planning and implementation. The research team applied rigorous methods to enhance the validity of results. However, extracting results from one setting can be a limitation as there is a risk that results will not be fully generalizable. However, it is likely that results will be applicable to other healthcare settings, as there are significant similarities between healthcare organizations and within EDs (28).

\section{Conclusion}

In conclusion, health care leaders' efforts to improve patient safety approaches such as medication management, necessitates realistic and useful action plans, and their implementation relies on manager and staff effort. The ability to commence and sustain improvement initiatives in an organization is directly affected by workforces' attitudes. Our findings suggest that extent to which health care leaders involve employees in the development of new medication management procedures and refocusing on concerns voiced by them directly effects their implementation and subsequent embedding. Since clinicians' experience significant stress in ED, launching new plans without their active involvement may exacerbate negative attitudes related to systemic challenges. Our findings suggest that PAR has the 
capacity to motivate the active involvement of diverse clinician groups enabling different viewpoints and expertise to be applied to the development of complex action plans.

\section{Declarations}

Ethics approval and consent to participate: The project was approved by the institutional review board of the university with which the first author was affiliated (approval code: IR.TUMS.FNM.REC.1397.124). The hospital in which the study was implemented was a University affiliated hospital. All potential participants were provided with study information and a consent form.

Consent for publication: Not applicable.

Availability of data and materials: The collected data in this study are confidential interview transcripts that are not available for sharing, but may be available from the corresponding author upon reasonable request.

Competing interests: The authors declare that they have no competing interests.

Funding: The present study is part of Fatemeh Bakhshi's PhD dissertation. This research has been supported by Tehran University of Medical Sciences \& health Services (grant number: 9321199002).

Authors' contributions: ANN, FB and SV designed the PAR project. FB and MB managed the project and collected all interviews and FGDs. FB and SV analysed the qualitative data. FB and RM were responsible for manuscript preparation. All authors contributed for reviewing the paper before submission.

Acknowledgements: We gratefully thank all participants, Dr Majid Hajimaghsoudi and Dr. Fatemeh Saghafi for their great collaboration during study.

\section{References}

1. Westbrook JI, Raban MZ, Walter SR, Douglas H. Task errors by emergency physicians are associated with interruptions, multitasking, fatigue and working memory capacity: a prospective, direct observation study. BMJ quality \& safety. 2018;27(8):655-63. http://dx.doi.org/10.1136/bmjqs-2017007333

2. Cabilan C, Hughes JA, Shannon C. The use of a contextual, modal and psychological classification of medication errors in the emergency department: a retrospective descriptive study. Journal of clinical nursing. 2017;26(23-24):4335-43. https://dx.doi.org/10.1111/jocn.13760

3. Pellegrin K, Lozano A, Miyamura J, Lynn J, Krenk L, Jolson-Oakes S, et al. Community-acquired and hospital-acquired medication harm among older inpatients and impact of a state-wide medication management intervention. BMJ quality \& safety. 2019;28(2):103-10. http://dx.doi.org/10.1136/bmjqs-2018-008418 
4. Bryant R, Chaar B, Schneider C. Differing clinical pharmacy service models: Quantitative and qualitative analysis of nurse perceptions of support from pharmacists. International journal of nursing studies. 2018;86:90-8. https://dx.doi.org/10.1016/j.ijnurstu.2018.04.003

5. Lisby M, Nielsen LP, Mainz J. Errors in the medication process: frequency, type, and potential clinical consequences. International Journal for Quality in Health Care. 2005;17(1):15-22. https://dx.doi.org/10.1093/intqhc/mzi015

6. Lee, Phan PH, Dorman T, Weaver SJ, Pronovost PJ. Handoffs, safety culture, and practices: evidence from the hospital survey on patient safety culture. BMC health services research. 2016;16(1):1-8. https://dx.doi.org/10.1186/s12913-016-1502-7

7. Steyrer J, Schiffinger M, Huber C, Valentin A, Strunk G. Attitude is everything?: The impact of workload, safety climate, and safety tools on medical errors A study of intensive care units. Health care management review. 2013;38(4):306-16. https://dx.doi/10.1097/HMR.0b013e318272935a

8. Naveh E, Katz-Navon T, Stern Z. The effect of safety management systems on continuous improvement of patient safety: The moderating role of safety climate and autonomy. Quality Management Journal. 2011;18(1):54-67. https://dx.doi.org/10.1080/10686967.2011.11918302

9. Lee E. Safety climate and attitude toward medication error reporting after hospital accreditation in South Korea. International Journal for Quality in Health Care. 2016;28(4):508-14. https://dx.doi.org/10.1093/intqhc/mzw058

10. Abayneh S, Lempp H, Hanlon C. Participatory action research to pilot a model of mental health service user involvement in an Ethiopian rural primary healthcare setting: study protocol. Research Involvement and Engagement. 2020;6(1):1-14. https://dx.doi.org/10.1186/s40900-019-0175-x

11. Abma T, Banks S, Cook T, Dias S, Madsen W, Springett J, et al. Participatory research for health and social well-being: Springer; 2019.

12. Kemmis S, McTaggart R, Nixon R. Introducing critical participatory action research. The action research planner: Springer; 2014. p. 1-31.

13. Fossey E, Harvey C, McDermott F, Davidson L. Understanding and evaluating qualitative research. Australian and New Zealand journal of psychiatry. 2002;36(6):717-32. https://dx.doi.org/10.1046/j.1440-1614.2002.01100.x

14. Nyumba T, Wilson K, Derrick CJ, Mukherjee N. The use of focus group discussion methodology: Insights from two decades of application in conservation. Methods in Ecology and evolution. 2018;9(1):20-32. https://dx.doi.org/10.1111/2041-210X.12860

15. Langlois S, Goudreau J, Lalonde L. Scientific rigour and innovations in participatory action research investigating workplace learning in continuing interprofessional education. Journal of interprofessional care. 2014;28(3):226-31. https://dx.doi.org/10.3109/13561820.2014.885003

16. Kallio H, Pietilä AM, Johnson M, Kangasniemi M. Systematic methodological review: developing a framework for a qualitative semi-structured interview guide. Journal of advanced nursing. 2016;72(12):2954-65. https://dx.doi.org/10.1111/jan.13031 
17. Graneheim UH, Lundman B. Qualitative content analysis in nursing research: concepts, procedures and measures to achieve trustworthiness. Nurse education today. 2004;24(2):105-12. https://dx.doi.org/10.1016/j.nedt.2003.10.001

18. Saldana J. Qualitative data analysis: the coding Manual for qualitative researchers. London: SAGE Publication Ltd; 2013.

19. Lincoln YS, Guba EG. Naturalistic inquiry. Newberry Park. CA: Sage; 1985.

20. Ajzen I. The theory of planned behavior. Organizational behavior and human decision processes. 1991;50(2):179-211.

21. McLaws M-L, Maharlouei N, Yousefi F, Askarian M. Predicting hand hygiene among Iranian health care workers using the theory of planned behavior. American journal of infection control. 2012;40(4):336-9. https://dx.doi.org/10.1016/j.ajic.2011.04.004

22. Haesebaert J, Samson I, Lee-Gosselin H, Guay-Bélanger S, Proteau J-F, Drouin G, et al. How to engage patients in research and quality improvement in community-based primary care settings: protocol for a participatory action research pilot study. Research involvement and engagement. 2018;4(1):30. https://dx.doi.org/10.1186/s40900-018-0113-3

23. Irajpour A, Farzi S, Saghaei M, Ravaghi H. Effect of interprofessional education of medication safety program on the medication error of physicians and nurses in the intensive care units. Journal of Education and Health Promotion. 2019;8. https://dx.doi.org/10.4103/jehp.jehp_200_19

24. Mansur JM. Medication safety systems and the important role of pharmacists. Drugs \& aging. 2016;33(3):213-21. https://dx.doi.org/10.1007/s40266-016-0358-1

25. Brown JN, Britnell SR, Stivers AP, Cruz JL. Focus: Drug Development: Medication Safety in Clinical Trials: Role of the Pharmacist in Optimizing Practice, Collaboration, and Education to Reduce Errors. The Yale Journal of Biology and Medicine. 2017;90(1):125.

26. Nelson JM, Cook PF, Ingram JC. Utility of the theory of planned behavior to predict nursing staff blood pressure monitoring behaviours. Journal of clinical nursing. 2014;23(3-4):461-70. https://dx.doi.org/10.1111/jocn.12183

27. Alzahrani N, Jones R, Rizwan A, Abdel-Latif ME. Safety attitudes in hospital emergency departments: a systematic review. International journal of health care quality assurance. 2019. https://dx.doi.org/10.1108/IJHCQA-07-2018-0164

28. Greenfield D, Nugus P, Travaglia J, Braithwaite J. Factors that shape the development of interprofessional improvement initiatives in health organisations. BMJ quality \& safety. 2011;20(4):332-7. http://dx.doi.org/10.1136/bmjqs.2010.044545

\section{Tables}


Table 1

Methods of PAR phases in this study

\begin{tabular}{|c|c|c|c|c|}
\hline & Stages & Activities & Performers & Periods \\
\hline \multirow{5}{*}{ Phase } & \multirow{2}{*}{$\begin{array}{l}0 . \text { Situation } \\
\text { analysis }\end{array}$} & Three FGDs ${ }^{\star}$ & Representatives & \multirow{2}{*}{$\begin{array}{l}\text { Sep- } \\
\text { Oct } \\
2018\end{array}$} \\
\hline & & for context analysis & $(n=8)$ & \\
\hline & 1. Plan & $\begin{array}{l}\mathrm{PCG}^{\star} \text { planned actions for } \\
\text { promoting } \mathrm{MM}^{\star}\end{array}$ & $\begin{array}{l}\text { PCG }(n=8) \text { and research } \\
\text { team }(n=3)\end{array}$ & $\begin{array}{l}\text { Nov } \\
2018\end{array}$ \\
\hline & 2. Action & $\begin{array}{l}\text { Planned actions performed by } \\
\mathrm{ED}^{*} \text { clinicians }\end{array}$ & $\begin{array}{l}\text { All participants }(n=85) \text {, } \\
\text { representative }(n=8) \text { and } \\
\text { research team }(n=3)\end{array}$ & $\begin{array}{l}\text { From } \\
\text { Dec } \\
2018\end{array}$ \\
\hline & $\begin{array}{l}3 . \\
\text { Observation }\end{array}$ & Forth FGD & Representatives $(\mathrm{n}=8)$ & $\begin{array}{l}\text { Mar } \\
2019\end{array}$ \\
\hline \multirow{6}{*}{$\begin{array}{l}\text { Phase } \\
\text { II }\end{array}$} & \multirow{2}{*}{$\begin{array}{l}\text { 4. } \\
\text { Reflection } \\
\text { 1. Re- } \\
\text { planning }\end{array}$} & $\begin{array}{l}\text { Reflecting on implemented } \\
\text { actions }\end{array}$ & Participants $(n=9)$ & \multirow{2}{*}{$\begin{array}{l}\text { Apr- } \\
\text { Jun } \\
2019\end{array}$} \\
\hline & & $\begin{array}{l}\text { Developing new strategies for } \\
\text { improvement in MM by PCG }\end{array}$ & $\begin{array}{l}\text { PCG }(n=8) \text { and research } \\
\text { team }(n=3)\end{array}$ & \\
\hline & 2. Action & $\begin{array}{l}\text { Implementation of planned } \\
\text { strategies }\end{array}$ & All participants $(n=85)$ & \multirow{2}{*}{$\begin{array}{l}\text { From } \\
\text { July } \\
2019\end{array}$} \\
\hline & \multirow{2}{*}{$\begin{array}{l}3 . \\
\text { Observation }\end{array}$} & Evaluation on implemented & \multirow[t]{2}{*}{ Representatives $(n=8)$} & \\
\hline & & actions by informal interviews & & $\begin{array}{l}\text { Oct } \\
2019\end{array}$ \\
\hline & $\begin{array}{l}\text { 4. Final } \\
\text { reflection }\end{array}$ & $\begin{array}{l}\text { Reflect on progress, advantages, } \\
\text { and changes related to } \\
\text { improvements by MM }\end{array}$ & Participants $(\mathrm{n}=10)$ & $\begin{array}{l}\text { Nov } \\
2019\end{array}$ \\
\hline
\end{tabular}


Table 2

Implemented actions in stage 3 of phase I.

\begin{tabular}{|c|c|c|c|c|c|}
\hline Action & $\begin{array}{l}\text { Responsible } \\
\text { lead }\end{array}$ & Purpose & Activities & $\begin{array}{l}\text { Target } \\
\text { group }\end{array}$ & Timelines \\
\hline $\begin{array}{l}\text { Interprofessional } \\
\text { courses on MM }\end{array}$ & $\begin{array}{l}\text { Clinical } \\
\text { pharmacist, } \\
\text { head of ED, } \\
\text { and } \\
\text { educational } \\
\text { supervisor }\end{array}$ & $\begin{array}{l}\text { To share } \\
\text { knowledge } \\
\text { of MM } \\
\text { guidelines } \\
\text { for providing } \\
\text { collaborative } \\
\text { integrated } \\
\text { medication } \\
\text { therapy }\end{array}$ & $\begin{array}{l}\text { Teaching main topics } \\
\text { of MM with focusing } \\
\text { on: } \\
\text { Guideline-based } \\
\text { prescribing and } \\
\text { administrating, } \\
\text { medication errors and } \\
\text { reporting, medication } \\
\text { safety, and patient } \\
\text { adherence to MM }\end{array}$ & $\begin{array}{l}\text { All } \\
\text { clinicians } \\
\text { in the ED }\end{array}$ & $\begin{array}{l}\text { From Dec } \\
2018 \text { to } \\
\text { end of } \\
\text { Feb } 2019\end{array}$ \\
\hline $\begin{array}{l}\text { Placement of } \\
\text { clinical } \\
\text { pharmacists in } \\
\text { ED }\end{array}$ & $\begin{array}{l}\text { Clinical } \\
\text { pharmacists }\end{array}$ & $\begin{array}{l}\text { To develop a } \\
\text { pharmacist- } \\
\text { led MM in } \\
\text { ED }\end{array}$ & $\begin{array}{l}\text { Reviewing } \\
\text { prescriptions of } \\
\text { specialists and } \\
\text { residents, reviewing } \\
\text { administration of } \\
\text { nurses, filling } \\
\text { designated checklists } \\
\text { for each review, } \\
\text { supervision on double } \\
\text { checking of high-risk } \\
\text { medications, providing } \\
\text { information and } \\
\text { feedbacks to clinicians } \\
\text { and patients }\end{array}$ & $\begin{array}{l}\text { All } \\
\text { clinicians } \\
\text { in the ED }\end{array}$ & $\begin{array}{l}\text { From Dec } \\
2018\end{array}$ \\
\hline
\end{tabular}


Table 3

Implemented actions in stage 2 of phase II.

\begin{tabular}{|c|c|c|c|c|c|}
\hline Actions & $\begin{array}{l}\text { Responsible } \\
\text { lead }\end{array}$ & Purpose & Activities & $\begin{array}{l}\text { Target } \\
\text { group }\end{array}$ & Timelines \\
\hline $\begin{array}{l}\text { Continuing } \\
\text { interprofessional } \\
\text { courses on MM } \\
\text { as previous } \\
\text { phase }\end{array}$ & Same a previous & $\begin{array}{l}\text { to stabilize } \\
\text { the newly } \\
\text { created } \\
\text { atmosphere } \\
\text { about MM }\end{array}$ & $\begin{array}{l}\text { Same as previous } \\
\text { by emphasizing on } \\
\text { participation of } \\
\text { new ED clinicians }\end{array}$ & $\begin{array}{l}\text { All ED } \\
\text { clinicians }\end{array}$ & $\begin{array}{l}\text { From } \\
\text { July } \\
2019 \\
\text { (monthly) }\end{array}$ \\
\hline $\begin{array}{l}\text { Developing more } \\
\text { structured and } \\
\text { evidence-based } \\
\text { guidelines for } \\
\text { MM }\end{array}$ & $\begin{array}{l}\text { Clinical } \\
\text { pharmacologists } \\
\text { in collaboration } \\
\text { with research } \\
\text { team }\end{array}$ & $\begin{array}{l}\text { To develop } \\
\text { more } \\
\text { structured } \\
\text { and } \\
\text { context- } \\
\text { based MM } \\
\text { guidelines }\end{array}$ & $\begin{array}{l}\text { For engaging other } \\
\text { clinicians in the } \\
\text { actions, an } \\
\text { announcement } \\
\text { about designing } \\
\text { new MM guidelines } \\
\text { were send to their } \\
\text { online portals. } \\
\text { They were } \\
\text { encouraged share } \\
\text { their ideas. Then, } \\
\text { the clinical } \\
\text { pharmacist } \\
\text { developed context- } \\
\text { based MM } \\
\text { guideline and rules. } \\
\text { The changes were } \\
\text { publicized in ED by } \\
\text { permission of } \\
\text { hospital } \\
\text { management } \\
\text { group. }\end{array}$ & $\begin{array}{l}\text { All ED } \\
\text { clinicians }\end{array}$ & $\begin{array}{l}\text { Aug-Sep } \\
2019\end{array}$ \\
\hline
\end{tabular}

\section{Supplementary Files}

This is a list of supplementary files associated with this preprint. Click to download.

- supplement5.docx 